\title{
ENKELE MARITIEME GEDACHTEN OVER DE DEFENSIE VAN CURAÇAO
}

\author{
DOOR
}

\section{GEORGE SEPPEN}

Onlangs drong tot ons door het gerucht van de aanstaande opheffing van het Marine-Commando in Curaçao, een Commando waaronder wij ruim drie en een half jaar met genoegen, respect, waardeering en dankbaarheid, hebben gediend. En terstond hebben wij ons afgevraagd, of de Marine, die de defensieve problemen daar te lande in de afgeloopen oorlogsjaren op voortvarende en uiterst tactische wijze in goede banen heeft geleid, de Curaçaosche defensie thans niet meer zou kunnen klaren. Men begrijpe ons goed. Wij stellen ons allerminst partij, maar wel moet het ons van het hart, dat - vooral na een ruim een jaar hernieuwden actieven dienst in Nederland - de gedetailleerde klaarheid en de rustige gedegenheid van Marine-regiem en Voorschrift-Koninklijke-Marine ons weldadig aandoen, als wij daaraan terugdenken.

In de verwarring, die in het bijzonder in den aanvang, op vrijwel alle terrein bij de landmacht in Nederland heerschte na de bevrijding en van welke confusie thans nog velen de kennelijke gevolgen met zich mee sleuren, was een terugtasten op de eenheid van denken en handelen in het voorschriftsysteem der Koninklijke Marine een ware verademing! Met erkentelijkheid zijn wij ons in dezen rommeligen tijd meer dan eens de - zij het misschien wat uitgemeten - maar zoo waarachtig objectieve sfeer van de toepassing van het tuchtrecht indachtig geweest en vele malen hebben wij er ons voordeel mee gedaan bij de uitzonderlijke feiten en misdragingen, die ter onzer kennis kwamen.

Immers de in wezen oude voorschriften der Koninklijke Marine, dragen niet alleen de gewisse kenteekenen eener waardevolle traditie, maar zijn bovendien de vrucht eener langdurige ervaring en routine. $\mathrm{Zij}$ geven vaste richting aan denken en doen en vormen een minutieuze leiddraad, waarop men - om een Marineterm te gebruiken - veilig kan dichtvaren.

$$
-65-
$$


En dat het juist aan deze vastheid in den beginne bij den opbouw van de Landmacht, terstond na de bevrijding, in Nederland volkomen ontbroken heeft, zal misschien wel niemand ontkennen. Improvisatie en een overmatigen drang om een nieuw geluid te willen laten hooren overheerschte te veel den nieuwen soldaat, die zich niet op een militair verleden kon beroepen.

Daarom was het destijds zoo goed,dat men bij den opbouw van de volkomen nieuwe Curaçaosche inheemsche krijgsmacht teruggegrepen heeft naar het gecodificeerde maritieme denken van het V. K. M., dat weliswaar vele vreemde en eigenaardige gebruiken meebracht, maar juist door den eerbiedwaardigen ouderdom en de toepasselijkheid, zoowel onder tropische, sub-tropische als Europeesche, omstandigheden, een waardig richtsnoer vormde.

Jammer echter - en dat is een leemte in de vóór-oorlogsche opleiding - dat totale onbekendheid met traditie en methodiek, met gebruiken en gewoonten, ook bij den beroepsofficier, vaak hoofdoorzaak van een volkomen afwijzende houding werden, tegenover al datgene, dat de Koninklijke Marine aan positieve waarden te bieden heeft, ook aan de Landmacht!

Inderdaad is het bij Marine ook niet alles goud, dat er blinkt en o.a. de vocabulaire van den Marineman doet soms wel ietwat gekunsteld aan. Walplaatsing en boordplaatsing zijn maar zonderlinge begrippen voor een gewoon mensch, vooral omdat de eerste lang niet altijd beteekent, dat men aan den wal zit en de tweede niet noodzakelijkerwijze het zich aan boord bevinden impliceert. Inside-information leerde ons, dat walplaatsing aan boord en boordplaatsing aan den wal wel degelijk mogelijk is en dat, wat de marineman theewater noemt, heel weinig met water en gewoonlijk ook niets met thee te maken behoeft te hebben. Wijders zou de stokoude bepaling van het ,uit de Marine naar huis jagen van een matroos als een eerlooze schelm", vermoedelijk menig vóór-oorlogsch landmachtdienstplichtige op een ideetje hebben gebracht, maar dit alles neemt niet weg, dat de duistere taal der varende en niet-varende zeelieden tenslotte is te leeren.

De Marine beschikt over iets, dat de Koninklijke Landmacht niet kent. Een product van tweeslachtigheid, een zeeman die soldaat is en een soldaat, die zeebeenen heeft.

Het zijn tweeslachtige wezens, die varen, zwabberen, wachtloopen en gewoon loopen, die kunnen dienen en tafeldekken, kanons afvuren en bovenal vechten, de phenomenen van het amphibie-gevecht, de afgeoefende en onvolprezen $\mathrm{M}$ a riniers! 
Zij zijn het geweest, die voor de defensie van Curaçao zulk een verdienstelijk werk hebben gedaan in een historisch tijdsgewricht, waardoor zij een blijvende plaats hebben verdiend in het insulaire gedeelte van de Nederlandsche West.

Het laat zich aanzien, dat in de na-oorlogsche militaire dislocatie geen blijvende plaats aan de Mariniers in Curaçao kan worden geboden, zoodat dit prachtig onderdeel der Koninklijke Marine binnenkort aldaar niet meer zal worden gezien. Dit is betreurenswaardig zoowel voor Curaçao als voor den Marinier.

De Marinier was min of meer autochthoon geworden op het vooroorlogsche Curaçao, verlevendigde niet alleen het straatbeeld, maar zijn verschijning was bovendien in hooge mate representatief, welke laatste factor vooral niet mag worden onderschat.

Ook de bevolking waardeerde dit frissche, vlotte en uitstekende gedisciplineerde militaire gezagsapparaat.

En toen wij in 1940 een radio-herdenking organiseerden vanwege het 275-jarig bestaan van het Korps Mariniers, in het Waterfort van Willemstad, betuigde iedereen zijn instemming, met uitzondering van één burger, die booze brieven aan het Hoofd van Politie schreef. Doch dit laatste geschiedde uitsluitend op gronden van - laten wij zeggen - een soort jalousie de métier en zeker niet uit gebrek aan waardeering voor het Korps.

De Mariniers kwamen in een roerigen tijd, toen Urbina de zwoele rust aan de Caraïbische Zee voor een wijle had verstoord en zij bevolkten het Waterfort tot aan hun vertrek in de afgeloopen oorlogsjaren, toen hun een taak werd opgelegd, die zij slechts na grondige opleiding in de Vereenigde Staten van Noord-Amerika konden aanvangen.

Er heerschte een echte Marinesfeer in het Waterfort, al die jaren door, en voor ons was het tijdstip van acht uur des morgens een telkenmale terugkeerend hoogtepunt. De vlaggeparade op de fortmuur, zoo goed te zien van de pontjesbrug af, was een dagelijksch silhouettenspel van bijzondere bekoring.

Na een twaalfjarig verblijf van een Detachement Mariniers op Curaçao opende zich in 1940 plotseling een wijd perspectief. Er moest een brokje Landmacht worden gebouwd, waartoe de inheemsche jongelingschap aangetrokken werd. Weliswaar liet het uit den tijd van Urbina's overval dateerende Vrijwilligers Korps Curaçao zich niet onbetuigd, maar er was dringend behoefte aan instructeurs en dit was in de eerste plaats de nieuwe 
taak voor den Marinier en zoo werd de basis van eén gedegen schiet- en exercitie-opleiding en later die voor een eenvoudige gevechtsopleiding door de Mariniers gelegd. En wat de Schutters in het gebiedsdeel Curaçao aan militaire waarde hebben geboden - en onze ervaringen in het na-oorlogsche-Nederland rechtvaardigen de meening, dat dezen niet laag moeten worden aangeslagen - danken zij in de eerste plaats aan den Marinier.

De eenvoud en het tempo der Mariniersinstructie paste wonderwel bij de mentaliteit en het bevattingsvermogen der jeugdige inheemsche bevolking en alhoewel de verhouding - qua personen - tusschen Mariniers en Schutters niet steeds goed kon worden genoemd, de methodiek der opleiding treft geen enkel verwijt. De afwijzende houding, die somtijds door personeel van de Landmacht op dit stuk werd aangenomen, berustte niet zoo zeer op redelijke constructieve critiek, dan wel op klaarblijkelijke gemakzucht en te weinig doorzettingsvermogen om zich in de bepalingen van het Voorschrift Koninklijke Marine in te werken.

De gedetailleerdheid van de Mariniersopleiding kon steeds aan allerlei locale omstandigheden worden aangepast, zoowel als aan factoren van psychologischen aard en het is apert onjuist te beweren, dat er van een zekere mate van onvereenigbaarheid sprake zou zijn geweest tusschen opleider en opgeleide.

Ook het veelvuldig geuite verwijt, als zoude de geringe sterkte van het Korps Mariniers in de voorschriften tot uiting komen door een zeer beperkte tactische gezichtskring met de daaruit voortkomende enge opvattingen der officieren, houdt geen steek, omdat juist in het Gebiedsdeel Curaçao de geringheid der personeelsterkte, de bescheiden quantiteit van het materieel en het hoogst beperkte territoir, niet alleen een smalle basis beteekenen, maar zelfs eischen.

Dat het „plafond” van het Marinierskader belangrijk hooger lag dan tot 1940 noodig was, is overduidelijk bewezen bij de herscholing in de U. S. A., toen de militaire waarde van het Korps op schier ontstellende wijze werd verhoogd, naar het voorbeeld der Amerikaansche „Marines”. Daar werden nieuwe taken voorgelegd, waarvan men in de rustige vóór-oorlogsche dagen nauwelijks had durven droomen.

Stelde de periode 1928-1940 speciale vredes-eischen, waaraan door de Mariniers ten volle werd voldaan en toonden zij zich in de prille oorlogsjaren op Curaçao en Aruba in staat te zijn tot het vormen van een kleine - vrij behoorlijke - strijdmacht uit inheemsch personeel gerecruteerd, de Amerikaansche scholing en 
de daarop gevolgde practische tropische ervaring maakt hen tot een uitgelezen schare, welke is voorbeschikt om het insulaire gebiedsdeel Curaçao aan een goed krijgsmachtorgaan - zoowel in tijden van oorlog als van vrede - te helpen.

Het is dan ook hierom, dat de terugkeer van de Mariniers naar Curaçao naar onze meening, als het ware voor de hand had moeten liggen.

Het voornemen bestaat echter om, gepaard met naar-huis-zending van de inheemsche troepen, te volstaan met een detachement troepen uit Europeesch Nederland, gerecruteerd uit oorlogsvrijwilligers en dienstplichtigen, wier korte opleiding inmiddels aangevangen is.

Ook het instituut van den Algemeen Militair Commandant, zijnde een Hoofdofficier der Koninklijke Marine, zal weldra tot het verleden behooren, om te worden vervangen door een Territoriaal Commandant van de Landmacht, een hoofd-officier van het Koninklijk Nederlandsch Leger.

En hiermede komen wij tot een gewichtige stap, n.l. de omzwaai van een Marine- naar een Landmacht-Commando in Curaçao!

Curaçao heeft in den loop zijner geschiedenis al heel wat instituten gekend en gemeenlijk keert datgene, dat voor den tijdgenoot gloednieuw lijkt, slechts in een anderen vorm uit het verleden terug. Dit laatste nu geldt zeer zeker ook voor de Defensie van Curaçao en eigenlijk is het niet te boud gesproken als men beweert, dat de historie van Curaçao in feite een lange reeks van defensie-ups and downs is geweest, met weinig hoogtepunten en angstig vele diepten.

Langs de kusten liggen talrijke plaatsen, die het tooneel van den strijd zijn geweest door meer dan drie eeuwen heen en de fortruïnes aan de baaien zijn daar de stille getuigen van. Maar al moge de strijd soms vrij hevig en het gevaar tamelijk groot zijn geweest, dit alles was en bleef secundair. Want het gevaar moest ergens vandaan komen, hetzij van verre dan wel van dichtbij, maar het kwam persé en onvermijdelijk van uit zee en elke bedreiging kreeg gestalte in de gedaante van een schip!

Want Maritiem zijn de gevaren, die Curaçao belagen en slechts maritiem kunnen zij in beginsel worden geweerd. Dat gold voorheen en dat geldt nu!

Of in dit maritieme verband het luchtwapen in feite niet moet praevaleeren boven oppervlakte-zeestrijdkrachten, is een vraag, die wij gaarne aan bevoegden overlaten, maar voor ons staat vast: 
In deze minuscule insulaire gebieden, met groote maritieme belangen, blijve de Landmacht een factor op het tweede plan en schakele men voor deze laatste het bestaande landmacht-apparaat der tnheemsche bevolking in. Dat het specifiek Amphibie-orgaan der Kon. Marine als secundaire macht boven een Landmachtapparaat prevaleert, ligt voor de hand. Het buitengaatsche denken is in de defensie problemen van Curaçao hooge eisch en dit laatste ligt de Landmacht nu eenmaal niet.

In een recent artikel van den Lt. Kolonel der Mariniers J. A. J. de Bruyn, over „Het wezen van den Marinier”, wordt op krachtige wijze de militaire potentie van dit Instituut bepleit en, sprekende over oorlogs- en vredes-taken van het Korps, belicht deze deskundige het onschatbaar belang van de amphibische specialisatie zijner leden.

„Het heeft van stonde af aan zijn diensten verricht in de marine maar ook steeds een zelfstandige taak daarbuiten gehad als expeditionnair machtsapparaat, maar er is ook nog een politioneele taak. De maritiem-militaire politiediensten behooren tot het arbeidsveld van den marinier en omvatten patrouille- en bewakingsdiensten, de handhaving van orde en discipline en het regelend en controleerend optreden op alle punten, waar marine is of belangen heeft, zoowel aan den wal als aan boord van het oorlogsschip. De verschillende taken van den marinier zijn historisch gegroeid en hebben den toets van enkele eeuwen doorstaan."

Alhoewel wij van meening zijn, dat de destijds om verschillende redenen niet plaats gehad hebbende uitzending van een contingent troepen, afkomstig van de Nederlandsche Antillen, naar Nederlandsch-Oost-Indië, een historisch verzuim is geweest, vooral nu daar te lande de politioneel-militaire taak wel zeer sterk op den voorgrond treedt, het had met de - helaas ongelukkigerwijze Schutterij genoemde - inheemsche troepen alsnog kunnen worden geprobeerd. Niet alleen omdat dit min of meer in de lijn ligt van een onafwendbaar aangebroken nieuw tijdperk in onze geschiedenis, maar ook, omdat het tegemoet komen kan aan een opkomend gezond gevoel van eigenwaarde onder de bevolking dezer eilanden.

Zeker, men geve leiding, men late het geheel niet los en men kweeke aanvoerders voor de nabije toekomst, terwijl een ieder op integriteit zal moeten worden getest, maar welk een kern van goede krachten zouden de, na korteren of langeren tijd uit de Oost terugkeerende, inheemsche troepen niet zijn geweest. Vele er- 
varingen en misschien ook wel desillusies rijker, maar in ieder geval verruimd van blik, een eigenschap die nu eenmaal den eilandbewoner, die nimmer buitengaats is geweest, niet is aangeboren en die hem tenslotte zoo broodnoodig dient te worden bijgebracht.

Het heeft niet zoo mogen zijn en wij herinneren ons nog levendig, dat op één der bereidverklaringen om naar de Oost te gaan, die informatorisch in het begin van 1943 werden gevraagd, een restrictie voorkwam, luidende: „Ben gaarne bereid, mits het niet tegen de uitgedrukte wil van de geheele inheemsche bevolking in Nederlandsch-Oost-Indië gaat."

Dit schreef een Europeesch Nederlander in 1943. Zijn opmerking werd min of meer genegeerd, omdat men toen nog zoo terdege van het tegendeel overtuigd was en algemeen op een joyeuse rentrée rekende, ook onder de insiders op Curaçao. Thans - nu de ontwikkeling van den toestand zoo volkomen anders blijkt te zijn - vragen wij ons af: Zou achter het opvallend geringe aantal bereidverklaringen van toen, niet iets zijn schuilgegaan van het vòor-voelen van een komende periode? Wij mogen aannemen dat aan de weinige bereidheid voornamelijk de typisch eilandelijke vrees ten grondslag lag; de angst voor het verlaten van het eigen kleine territoir, iets dat bij den inheemschen soldaat zelfs een rol speelde, wanneer hij van het eene eiland naar het andere moest worden overgeplaatst.

De Antillische hokvastheid is een even merkwaardig als diepgaand verschijnsel, maar toch: Heeft misschien onderbewust en nauwelijks definieerbaar, den inheemschen soldaat dat wonderlijke gevoel van sluimerende solidariteit vervuld, dat leeft onder alle menschen, hetzij blank, dan wel bruin of zwart, dat gevoel van huivering als het om een, wellicht volkomen verkeerd begrepen en zich zeker op gevaarlijke wijze ontwikkelende, maar toch in beginsel hevig verlangde vrijheid gaat?

Daarom past binnen het kader van dit artikel oprechte hulde aan de inheemsche soldaten uit het zustergebied Suriname, die wel zijn gegaan en die, naar wij van ganscher harte hopen, als zij terugkeeren in hun prachtig land, een waarachtige belooning zullen vinden in het tot nu toe nog steeds veel te stiefmoederlijk bedeelde Nederlandsch Guyana, dat in ons midden in feite een eereplaats verdient!

Keeren wij tenslotte onze maritieme gedachten over Curaçao naar de realiteit, dan liggen de feiten zoo, dat over heruitzending 
van Mariniers terdege is gepeinsd, echter zonder resultaat.

Er zullen binnenkort zoogenaamde „Rijkstroepen” vertrekken (zonderlinge benaming overigens) naar De West, reeds in spoedopleiding zijnde aan den Westerweg in Alkmaar. Twee compagnieën voor Curaçao en één voor Suriname. Wij willen Suriname in dit artikel buiten beschouwing laten, omdat daar te lande, o. i. wel degelijk de Landmachtgedachte dient te worden vooropgesteld.

Van verre hebben wij de recruteering dezer Rijkstroepen gedeeltelijk gadegeslagen. Een droevig geval. Oproepingen aan den loopenden band, zonder commentaar en zonder toelichting, voor velen een sprong in het duister, om toch maar weg te kunnen gaan en misschien wel om De Oost te kunnen ontloopen.

Van de enkelen, die zich meldden bij ons voormalig onderdeel, was er niet één, die blijk van waarachtige belangstelling gaf, of zelfs maar even over De West wenschte te worden ingelicht.

Lieden met gebruiksaanwijzing, zooals men in militaire kringen zegt, een enkele desperado, of een jongen met problemen thuis. Natuurlijk zullen er puike soldaten onder hen zijn, en wellicht komt de interesse op den duur, maar toch hebben wij ons in gemoede afgevraagd: Waarom niet juist nu eens naar echte belangstelling gespeurd en gepuurd uit het beste van het beste, omdat het om een uitstekend deel van Nederland in Amerika gaat!

Men verwachtte van ons geen voor-oordeel of zelfs maar een wrange reserve ten aanzien van wie dan ook, maar als voormalig bewoner van nagenoeg alle deelen en deeltjes van de West, hebben wij ons ten deze andermaal diep teleurgesteld gevoeld.

Wel schrijft het dagblad De Tijd in zijn 22 Novembernummer met zeker enthousiasme over het Kamp „Detachement WestIndië", maar er schuilt iets gekunstelds, iets onechts, in de volgende bewering:

„De jongens, zoo goed als alle vrijwilligers, verbinden zich voor twee jaar. Zij zijn afkomstig van de Gezagstroepen en andere legeronderdeelen en bestemd voor dat deel des Rijks, dat in het Moederland betrekkelijk nog het minst bekend is; hun opdracht is niet zoozeer een militaire, maar in hoofdzaak gericht op moreele hulpverleening. Twee compagnieën zijn bestemd voor Curaçao, terwijl de derde naar Suriname gaat."

Wat overigens met die "moreele hulpverleening" wordt bedoeld is ons vooralsnog een raadsel.

Een opleiding in een luttele spanne tijds van jonge soldaten, 
wier zuiver militaire eigenschappen zeker nog niet excellent mogen worden genoemd, zonder gedegen voorbereiding op een speciale taak, waarin van hun optreden, zoowel individueel, als en masse, enorm veel moet worden verwacht, komt ons - eerlijk gezegd - als een gewaagd experiment voor.

Bijna zouden wij geneigd zijn te zeggen, dat men wederom in het oude schuitje vaart met die aloude gedachte van ,het valt even mee", waaraan wij in het verleden telkenmale hebben gelaboreerd, tot onze schade en, somtijds ook, schande.

Hoeveel rationeeler zoude het zijn geweest, wanneer De West nu eindelijk eens bedacht werd met een volwaardig en representatief Marine-apparaat en daarnaast, voorzoover het Curaçao betreft, met de inheemsche troepen in de tweede ban. Voor Suriname bepleiten wij daarentegen voornamelijk een uitstekend Landmacht-instituut, waarbij de Koninklijke Marine haar prachtige aanvullende en meer in het bijzonder representatieve taak zou kunnen opnemen.

Dat daarbij ons prestige en niet de knibbelarij den doorslag geven moet, is duidelijk

Men vergete nimmer, dat het in onze groote tijden steeds de Marine was, de ijzeren mannen op de houten schepen, die Nederland zijn plaats in het wereldbestel deden innemen en al verlangen wij allerminst terug naar imperiale-, koloniale- of andere vergane perioden, voor ons geldt toch nog altijd het ,noblesse oblige", dat in onze dagen weliswaar in gansch andere beteekenis dan die van macht en kracht alleen moet worden gezien, maar dat nochthans, ook in de moderne, waarlijk toe te juichen, komende vernieuwing, groote offers en verplichtingen inhoudt.

Dat De West op den duur een door personeel en materiaal uitblinkend krijgsmacht-apparaat moge deelachtig worden, waarin de inheemsche bevolking een belangrijk aandeel heeft, is onze hartewensch.

Maastricht, December 1946.

\section{Mr. DR. VAN HAAREN $†$}

De regelen, in de Dec. 1946-aflevering gewijd aan mr. dr. F. L. J. van Haaren, waren van de hand van jhr. L. C. van Panhuys. 